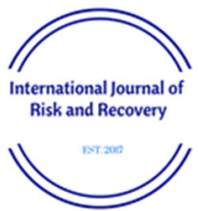

\title{
Vicarious trauma and occupational hazard for forensic mental health professionals
}

\author{
John Bradford, ${ }^{1,2,3}$ Gary Chaimowitz ${ }^{1,2}$ \\ ${ }^{1}$ McMaster University, Department of Psychiatry and Behavioural Neurosciences, Hamilton, Canada; ${ }^{2}$ Forensic Psychiatry \\ Program, St. Joseph's Healthcare, Hamilton, Canada; ${ }^{3}$ University of Ottawa, Department of Psychiatry, Ottawa, Canada
}

Vicarious trauma or vicarious traumatization is the effects on a health-care worker that results from the empathic engagement or therapeutic relationship with clients or patients and their reports of traumatic experiences. The term was coined in response to the experience of psychotherapists working with trauma survivors and is widely attributed to McCann and Pearlman 1990 [1]. They developed a constructivist selfdevelopment theory discussing therapist reactions to clients' traumatic material. They described that vicarious trauma can be understood as related to the graphic and painful material trauma clients portray to the therapists as well as the therapists unique cognitive schemas or beliefs and assumptions about self and others [1]. This theory has developed, has subsequently been described as compassion fatigue and has been subject to a considerable amount of research since this early description [2-18]. It has also focused on various professionals, including mental health professionals, and their vulnerability from working with a variety of clients or patients [4-6,8-10,12-14,19]. In this context, forensic mental health professionals are not specifically mentioned, although it is quite clear that the nature of the work that they do would make them vulnerable to vicarious trauma and "compassion fatigue."

The authors argue that forensic mental health professionals and other professionals who work in the criminal justice system are distinctly at risk for exposure to highly traumatizing material as part of forensic psychiatric and mental health evaluations. This material includes explicit post-mortem pictures, videos of the crime or crime scene and, in rare circumstances, sexual homicide perpetrators' records of their acts.

With technological advances and social media, the ability to record in vivid detail and to share this material has significantly increased the potential for vicarious trauma. What was once the occasional grainy black-and-white pictures became the colour photographs before becoming the multitude of digital pictures and videos covering every angle and every aspect often multiple times. Digital resolution of image capture and display improved. Ease of transmission and storage means more people can view and share. Curiosity and teaching contributed to a wider sharing of this material, well before reports of increasing vicarious trauma sequelae began to emerge. Experts in the forensic psychiatry field have often viewed reading about and viewing crime scenes as an interesting and expected part of their work. However, the insidious creep of more images and more details allowed progression of the effects of vicarious trauma or vicarious traumatization to go unreported for so long.

Particularly traumatizing has been the digital capture of crimes against children, especially sexual crimes including child pornography. The less frequent auditory or visual depiction of crimes in progress, where the terror of the victim is captured in full sensory mode, can be hard to erase from memory. Even now, the mere cellphone recording by members of the public witness to crimes and death and played out on TV screens can be disturbing. 
It is in this new world that we find ourselves. Owing to the bravery of experts speaking out about their experiences with the mental health consequences of dealing with reading about these crimes, hearing from victims and seeing recorded material, we in forensic psychiatry should firstly acknowledge that vicarious trauma is an occupational hazard in the forensic psychiatry domain. We can and should develop guidelines for the management of forensic psychiatry material. We should also put in place accessible supports for those experiencing vicarious trauma.

\section{References}

1. McCann LP, Pearlman LA. Vicarious traumatization: A framework for understanding the psychological effects of working with victims. J Traum Stress; 1990;3(1):131-49.

2. Borenstein M. [Compassion fatigue and vicarious trauma in caregivers]. Soins Pediatr Pueric. 2018;39(304):13-15.

3. Brockhouse R, Msetfi RM, Cohen K, Joseph S. Vicarious exposure to trauma and growth in therapists: the moderating effects of sense of coherence, organizational support, and empathy. J Trauma Stress. 2011;24(6):735-42.

4. Cosden M,Sanford A, Koch LM, Lepore CE. Vicarious trauma and vicarious posttraumatic growth among substance abuse treatment providers. Subst Abus. 2016;37(4):619-624.

5. Crothers, D. Vicarious traumatization in the work with survivors of childhood trauma. J Psychosoc Nurs Ment Health Serv. 1995;33(4):9-13.

6. Devilly GJ, Wright R, Varker T. Vicarious trauma, secondary traumatic stress or simply burnout? Effect of trauma therapy on mental health professionals. Aust $N$ Z J Psychiatry. 2009;43(4):373-85.

7. Jenkins SR,Baird S. Secondary traumatic stress and vicarious trauma: a validational study. J Trauma Stress. 2002;15(5):423-32.

8. Keenan P, Royle L. Vicarious trauma and first responders: a case study utilizing eye movement desensitization and reprocessing (EMDR) as the primary treatment modality. Int J Emerg Ment Health. 2007;9(4):291-8.
9. Mathieu F. Occupational hazards: compassion fatigue, vicarious trauma and burnout. Can Nurse. 2014;110(5):12-3.

10. Mishori R, Mujawar I, Ravi N. Self-reported vicarious trauma in asylum evaluators: a preliminary survey. $J$ Immigr Minor Health. 2014;16(6):1232-7.

11. Munger T, Savage T, Panosky DM. When caring for perpetrators becomes a sentence: recognizing vicarious trauma. J Correct Health Care. 2015;21(4):365-74.

12. Palm KM, Polusny MA, Follette VM. Vicarious traumatization: potential hazards and interventions for disaster and trauma workers. Prehosp Disaster Med. 2004;19(1):73-8.

13. Pearlman LA. Re. Social work in oncology-managing vicarious trauma-the positive impact of professional supervision. Letter to the editor. Soc Work Health Care. 2014;53(8):693-4.

14. Raunick CB, Lindell DF, Morris DL, Beckman T. Vicarious trauma among sexual assault nurse examiners. $J$ Forensic Nurs. 2015;11(3):123-8; quiz E1.

15. Silveira FS, Boyer W. Vicarious resilience in counselors of child and youth victims of interpersonal trauma. Qual Health Res. 2015;25(4):513-26.16. Way I, VanDeusen KM, Cottrell T. Vicarious trauma: predictors of clinicians' disrupted cognitions about self-esteem and self-intimacy. J Child Sex Abus. 2007;16(4):81-98.

17. Way I, VanDeusen KM, Martin G, Applegate B, Jandle D. Vicarious trauma: a comparison of clinicians who treat survivors of sexual abuse and sexual offenders. $J$ Interpers Violence. 2004;19(1):49-71.

18. Woolhouse S, Brown JB, Thind A. "Building through the grief": vicarious trauma in a group of inner-city family physicians. J Am Board Fam Med. 2012;25(6):840-6.

19. Makadia R, Sabin-Farrell R, Turpin G. Indirect exposure to client trauma and the impact on trainee clinical psychologists: Secondary traumatic stress or vicarious traumatization? Clin Psychol Psychother. 2017;24(5):1059-1068.

\section{Corresponding author}

John Bradford, Forensic Psychiatry Program, St. Joseph's Healthcare Hamilton, ON L9C OE3, Canada - email: jbradford@stjosham.on.ca. 